\title{
Patient Perspective, Complexities, and Challenges in Managed Care
}

\author{
Saira A. Jan, MS, PharmD
}

\begin{abstract}
BACKGROUND: Lack of coordination of care is one of the largest obstacles involved with treating opioid dependence. Physicians also face the challenges of managing comorbidities and dealing with relapse.
\end{abstract}

OBJECTIVE: To examine the clinical, economic, and humanistic factors involved in treating opioid dependence.

SUMMARY: Despite the extensive utilization of narcotic analgesics, pain is often uncontrolled. Effective pain management and coordination of care is essential in treating pain patients, as patients who abuse pain medications consume more health care resources than nonabusers. Patients who abuse are 2.3 times more likely to present at the emergency department and 6.7 times more likely to be hospitalized than nonabusers. Managed care organizations are now incorporating integrated approaches to treating pain and substance abuse disorders, realizing that patients must be looked at as a whole, considering alternative and behavioral therapies in addition to pharmacological treatments. They are also able to assess patterns of abuse using pharmacy claims data and alert physicians to potential problems by making use of prescription monitoring programs. Physicians who treat chronic pain must utilize strategies to minimize the risk of developing dependence on opioids, and practitioners treating opioid dependence must employ policies to optimize outcomes. Such strategies include developing pain contracts; performing random urine screenings and pill counts; and setting goals of therapy and re-evaluating patients throughout treatment. Plans must be in place in the event of relapse, as well.

CONCLUSION: In order to be successful in managing opioid dependence, physicians, employers, and managed care organizations must work together to provide an integrated approach to treatment.

J Manag Care Pharm. 2010;16(1-b):S22-S25

Copyright $\odot 2010$, Academy of Managed Care Pharmacy. All rights reserved.

\section{Author}

SAIRA A. JAN, MS, PharmD, is Clinical Director, Blue Cross Blue Shield of New Jersey, and Associate Professor at the Ernest Mario School of Pharmacy of Rutgers, the State University of New Jersey.

AUTHOR CORRESPONDENCE: Saira A. Jan, MS, PharmD, Director of Clinical Pharmacy Management, Horizon Blue Cross Blue Shield of New Jersey, Newark, NJ 07105-2200. Tel.: 973.466.6192;

Fax: 973.466.4665. E-mail: Saira_Jan@horizon-bcbsnj.com.

\section{DISCLOSURES}

This activity was funded through an educational grant from Reckitt Benckiser Pharmaceuticals, Inc.

The author acknowledges editorial assistance from Lance Nicholls, PharmD, and Lisa Bragaw, RPh, Lancer Solutions, LLC, New Milford, Connecticut; and Janet Cline, RPh, and Dana Frazier, Creative Educational Concepts, Inc., Lexington, Kentucky.
$\mathrm{T}$ here are many obstacles in managing opioid dependence, including selecting the appropriate treatment plan, resolving the patient's pain, and identifying the options for alternative treatments. Physicians are left trying to streamline a patient population that may be abusing opioids and place them in programs that could benefit them. Quite often, pharmacologic treatment of opioid dependence isn't enough, and psychosocial treatment services will be required. Offices should make sure that they have the proper education, personnel, and resources to be able to provide psychosocial services in conjunction with the medical therapy. This is in addition to the training the physician needs in order to provide office-based opioid treatment. ${ }^{1,2}$

\section{Goals of Pain Management}

Pain is increasingly recognized as the fifth vital sign; a patient's level of pain should be evaluated at every visit along with other vitals such as blood pressure and pulse. ${ }^{3}$ The need for improvement in pain management is well known. Despite the availability of many pain medications and the increased utilization of opioid analgesics, the level of unrelieved pain remains unacceptably high. ${ }^{4}$ While there is disagreement over whether the goal of pain management should be to improve patients' day-to-day functioning or reduce their pain, the American Pain Society feels that the primary goal should be treating patients to achieve increased levels of functioning. ${ }^{5}$ Reducing the patient's pain level may improve quality of life by increasing function and reducing suffering. ${ }^{5}$ There are many barriers to effective management of pain which can lead to inadequate pain relief, can increase risk of dependence, and adds additional cost to the health care system. ${ }^{6}$ There is currently no set standards for re-evaluating patients receiving pain medications. Goals should be set on an individual basis and re-evaluated regularly. If these goals are not achieved, the treatment plan should be re-evaluated and changes to treatment made in order to meet goals.

\section{Challenges in Managed Care}

Inappropriate Management. One of the biggest challenges is the inappropriate management of patients. There is little to no coordination of care; many patients have multiple prescribers, and there are high rates of abuse and diversion. ${ }^{7}$ Studies have reported a lack of knowledge regarding pain management principles among physicians of all levels. ${ }^{8}$ Many prescribers report hesitancy in prescribing opioids because of concerns surrounding adverse effects, respiratory depression, and risk of dependence. ${ }^{4}$ As recently as 2000, pain management and end-of-life issues were not emphasized in medical school curricula. In 2003, a mandate was issued by the Liaison Committee on Medical Education recommending that all medical students go through formal training in end-of-life issues and palliative care, and residency training in these areas is now required by the American Board of Internal Medicine. ${ }^{4}$ 
Lack of Coordination of Care. The lack of coordination of care in chronic pain treatment is critical. Often a primary care physician is prescribing opioids, but the patient may see other practitioners who also prescribe pain medications. The traditional approach of opioid management within a managed care organization (MCO) has been to look at medical and pharmacy claims data and try to identify multiple prescribers and multiple pharmacies for a patient receiving opioids. Many patients with drug-seeking behaviors will go to multiple pharmacies, often paying cash for their opioids, in order to obtain more medication or to avoid being caught going to multiple prescribers ("doctor shopping"). If the claims are not being billed to the $\mathrm{MCO}$ or pharmacy benefit managers (PBM), it is much more difficult to be tracked, as MCOs can only report on the prescriptions for which they are being billed. If a MCO identifies a patient going to multiple prescribers and pharmacies, they may limit the patient to 1 pharmacy, or notify the prescribing physicians. MCOs collaborate with PBMs to perform drug utilization reviews, individual profile reviews, and perform reviews for fraud and abuse. MCOs and PBMs may also look closely at high cost members-those members who utilize the top $10 \%$ of resources. However, the problem with opioid dependence is much larger than just cost. Patients who have substance abuse disorders utilize substantially more health care resources than nonabusers. For example, they are 6.7 times more likely than nonabusers to be hospitalized, and 2.3 times more likely to utilize the emergency department. ${ }^{9}$ Emergency department (ED) physicians, like other health care providers, often struggle to distinguish patients with legitimate pain from those reporting pain fraudulently to obtain narcotic prescriptions for abuse or diversion, as pain is principally subjective. ${ }^{10}$ There is also a disconnect in tracking patients who utilize the ED for obtaining pain medications, as they are not identified on prescription monitoring programs set up by the MCOs. The medications dispensed in the hospital or ED are billed through the patient's'medical benefit, not the prescription benefit.

Several organizations are now incorporating an integrated approach to chronic pain management, including looking at patients as a whole (including a behavioral component), implementing management programs for existing disease-state conditions, and developing programs to manage individual patients as a whole. Physicians need to continue to monitor their patients, both for pain and for aberrant drug-related behavior. Formal opioid treatment agreements between the physician and the patient should be in place so the patient knows what is acceptable and expected of them, while protecting the physician as well. ${ }^{5}$ Contracts such as these help keep the lines of communication open.

Aberrant Drug-Related Behaviors. Aberrant drug-related behaviors cover a broad spectrum, from aggressively seeking medications and increasing dosages without physician approval to injecting or snorting medications intended for oral use and illegal activities such as selling drugs. The more aberrant the behavior, the higher the risk of developing addiction. ${ }^{9}$ Risk tools described earlier in this supplement for assessing aberrant behavior should be utilized. To reduce or avoid the risk of abuse, physicians must implement adherence monitoring programs. ${ }^{11}$ Studies have shown that monitoring compliance with random pill counts, for example, and random urine screening results in noteworthy reductions in utilization of illicit drugs. ${ }^{12}$

Fishbain et al. performed an evidenced-based review of studies of abuse, addiction, and aberrant drug-related behavior seen in patients with chronic pain and taking oral opioid medications. ${ }^{13}$ Among 5 studies of chronic pain patients $(n=15,442)$, the average percentage of aberrant drug-related behaviors (as determined by urine toxicology screening) was $20.4 \%$. It was noted that aberrant drug-related behaviors were identified at a higher rate by urine toxicology screenings than by observation of patient behavior (20.4\% vs. $11.5 \%$ ). The $11.5 \%$ was determined by a review of 17 studies ( $n=2,466$ chronic pain patients) that identified aberrant drug-related behavior through observation alone. These results further emphasize the need for doctors to perform routine urine screenings on their opioid patients. ${ }^{5,13}$ Patients should know at the beginning of treatment that these tests will be done, and that they are for their benefit, similar to how diabetics test their blood sugar to make sure they are staying on track with their therapy.

Primary care physicians should be educated on when a patient needs to be referred to a pain management specialist. Likewise, if a pain management specialist has identified an issue, he/she should know when to refer the patient to appropriate resources or services.

Management of Comorbidities. Psychiatric disorders are commonly seen in patients with opioid dependence. Opioid dependence is commonly characterized by frequent relapse and results in social and health consequences, including unemployment, criminal behaviors, and blood-borne infections (HIV) from injecting opioids illicitly using dirty or shared needles. ${ }^{14} \mathrm{~A}$ recent non-interventional observational study looking at depressed patients and satisfaction with methadone maintenance treatment reported that patients with depression experienced more opioid withdrawal symptoms compared with nondepressed patients. ${ }^{14}$ This correlates well with other studies, such as those performed by Mitchell, et al., and Schreiber, et al., that show poorer outcomes with methadone maintenance therapy in depressed patients. ${ }^{14,15,16}$ These findings further emphasize the need to treat comorbid conditions such as depression for optimal patient outcomes. ${ }^{14}$ Antidepressants help with concomitant depression, but many are now being used off-label to treat chronic pain. ${ }^{5}$ Incorporating appropriate antidepressants into an opioid dependent patient's regimen may be an effective treatment strategy on multiple levels. ${ }^{5}$

Negative emotional states may be strong predictors of relapse in opioid dependence. As such, addressing a patient's coping 


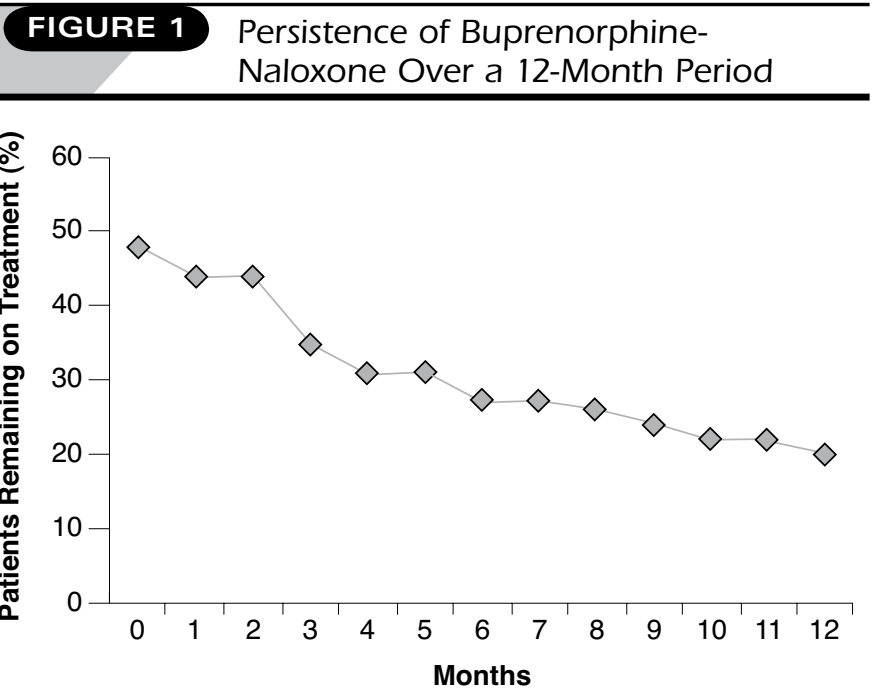

Source: Kaur AD, McQueen A, Jan S. J Manag Care Pharm. 2008;14(2):186-94.18

skills is important. ${ }^{17}$ A study by Chaney and Roszell examined an all-male veteran population on methadone for opioid dependence and found they had few coping skills and tended to utilize unsuitable strategies when coping with high-risk circumstances. The study group participated in a 12-week coping skills training program. After completing the training, $70 \%$ remained in the methadone treatment program, and depressive symptoms and avoidant (or maladaptive) coping diminished. ${ }^{18}$

Relapse. Unfortunately, relapse is extremely common in treating opioid dependence. Continued use of opioids causes chemical changes in a person's brain that cause negative emotions and cravings when a patient tries to stop using. ${ }^{19}$ During times of stress, a patient may relapse, especially if they do not have good coping skills. ${ }^{20}$ Relapse is particularly common among patients who abuse more than 1 substance. ${ }^{21}$ Remaining in treatment is important to success. ${ }^{21}$ Regrettably, only 1 in 10 patients with substance abuse receives treatment, and of those, only 1 in 7 complete a program, according to the Network for the Improvement of Addiction Treatment, a nonprofit agency. ${ }^{21,22}$ Interestingly, those who do complete treatment are often patients who have insurance that covers their treatment. ${ }^{21}$ (Figure 1)

Patients who are employed tend to be more compliant with treatment, as they may be motivated by having a supportive employer and a job to return to. Among employed people who sought help for opioid dependence, 93\% said their employer knew of their treatment, 55\% had an employee assistance program available to them, and $65 \%$ continued to work for the same employer 1 year after treatment, and about half abstained from substance abuse for more than a year. ${ }^{3}$ In a study of human resource professionals, $85 \%$ said their company would benefit from education programs in the workplace that would help them identify and help employees who are suffering from a substance abuse disorder. ${ }^{3}$

Due in part to concerns about ramifications at work, employed persons with substance abuse disorders may not seek help. ${ }^{3}$ Employees need to know about assistance programs available to them, and that these programs must adhere to strict confidentiality guidelines. ${ }^{3}$ Missed days from work, changes in behavior, changes in work habits, and high accident rates are all signs that an employee may need some assistance. Employers, especially human resources departments, should be educated on identifying signs that an employee may need help with a substance abuse disorder and on how to assist employees in receiving the required help or health benefits in treating the disorder. Helping employees regain their ability to function in their jobs helps the employer; in addition to the costs associated with loss of productivity, the cost of firing that employee and replacing the position (including recruitment and training costs) can also be significant. ${ }^{3}$

\section{Conclusion}

Patients who are opioid dependent utilize costly health care resources. An integrated approach to treatment is essential to reduce these costs and improve outcomes for these patients. Physicians should utilize contracts and monitoring policies for all their pain patients, as well as opioid-dependent patients. Risk stratification and assessing aberrant drug related behaviors are important and can be done with tools currently available to practitioners. ${ }^{9} 11,12$ Pain and opioid dependent patients must be provided with tools to enable them to cope with stressful situations and treatment for comorbid conditions, such as depression. ${ }^{9}, 12$ Patients must be motivated to stay in therapy using integrated approaches to therapy including behavior modifications, employee assistance programs, and coverage of treatments by managed care organizations. ${ }^{3,19,21}$

\section{REFERENCES}

1. DHHS. Substance Abuse and Mental Health Services Administration Center for Substance Abuse Treatment. Clinical guidelines for the use of buprenorphine in the treatment of opioid addiction-treatment improvement protocol TIP 40. Publication no. (SMA) 04-3939. Available at: http:// www.ncbi.nlm.nih.gov/books/bv.fcgi?rid=hstat5.section.72303. Accessed January 24, 2010

2. Manlandro JJ. Buprenorphine for office-based treatment of patients with opioid addiction. J Am Osteopath Assoc. 2005;105(6 Suppl 3):S8-13

3. Cross MA. Employers address opioid dependence: companies tackle problems in the workplace with new ideas and traditional programs. Manag Care. 2009;1(1):21-27.

4. Scott E, Borate U, Heitner S, et al. Pain management practices by internal medicine residents - a comparison before and after educational and institutional interventions. Am J Hosp Palliat Care. 2009;25(6):431-39.

5. American Chronic Pain Association. ACPA chronic pain medications supplement 2008. Available at: http://www.theacpa.org/documents/ACPA\%20 Chronic\%20Pain\%20Medications\%20Supplement\%202008.pdf. Accessed January 24, 2010 
6. Gordon DB, Dahl JL, Miaskowski C, et al. American Pain Society recommendations for improving the quality of acute and cancer pain management: American Pain Society quality of care task force. Arch Intern Med. 2005;165(14):1574-80. Available at: http://archinte.ama-assn.org/cgi/ reprint/165/14/1574. Accessed January 20, 2010.

7. DHHS. Substance Abuse and Mental Health Services Administration. Center for Substance Abuse Treatment. Office of Applied Studies. Results from the 2007 national survey on drug use and health: national findings. NSDUH Series H-34, DHHS publication no. SMA 08-4343. September 2008 Available at: http://oas.samhsa.gov/nsduh/2k7nsduh/2k7Results.cfm\#TOC. Accessed January 24, 2010.

8. Chaitowitz M, Tester W, Eiger G. Use of a comprehensive survey as a first step in addressing clinical competence of physicians-in-training in the management of pain. J Opioid Manag. 2005;1(2):98-108.

9. O'Toole TP, Strain EC, Wand G, et al. Outpatient treatment entry and health care utilization after a combined medical/substance abuse intervention for hospitalized medical patients. J Gen Intern Med. 2002;17(5):334-40.

10. Parente ST, Kim SS, Finch MD, et al. Identifying controlled substance patterns of utilization requiring evaluation using administrative claims data. Am J Manag Care. 2004;10(11):783-90.

11. Trescot AM, Boswell MV, Atluri SL, et al. Opioid guidelines in the management of chronic noncancer pain. Pain Physician. 2006;9(1):1-39. Available at: http://www.painphysicianjournal.com/2006/january/2006;9;1-40.pdf. Accessed January 24, 2010.

12. Manchikanti L, Manchukonda R, Pampati V, et al. Does random urine drug testing reduce illicit drug use in chronic pain patients receiving opioids? Pain Physician. 2006;9(2):123-29.

13. Fishbain DA, Cole B, Lewis J, et al. What percentage of chronic nonmalignant pain patients exposed to chronic opioid analgesic therapy develop abuse/addiction and/or aberrant drug-related behaviors? A structured evidence-based review. Pain Med. 2008;9(4):444-59.

14. Elkader AK, Brands B, Dunn E, et al. Major depressive disorder and patient satisfaction in relation to methadone pharmacokinetics and pharmacodynamics in stabilized methadone maintenance patients. J Clin Psychopharmacol. 2009;29(1):77-81.
15. Mitchell TB, Dyer KR, Newcombe D, et al. Subjective and physiological responses among racemic-methadone maintenance patients in relation to relative (S)- vs. (R)-methadone exposure. J Clin Pharmacol. 2004;58(6):60917.

16. Schreiber S, Peles E, Adelson M. Association between improvement in depression, reduced benzodiazepine (BDZ) abuse, and increased psychotropic medication use in methadone maintenance treatment (MMT) patients. Drug Alcohol Depend. 2008;92(1-3):79-85.

17. Avants SK, Warburton LA, Margolin A. The influence of coping and depression on abstinence from illicit drug use in methadone-maintained patients. Am J Drug Alcohol Abuse. 2000;26(3):399-416.

18. Chaney EF, Roszell DK. Coping in opiate addicts maintained on methadone. In: Shiffman S and Wills TA, eds. Coping and Substance Abuse. Orlando, FL: Academic Press; 1985:267-93.

19. Kaur AD, McQueen A, Jan S. Opioid drug utilization and cost outcomes associated with the use of buprenorphine-naloxone in patients with a history of prescription opioid use. J Manag Care Pharm. 2008;14(2):18694. Available at: http://www.amcp.org/data/jmcp/JMCPMaga_March\%20 08_186-194.pdf.

20. Kakko J, Grönbladh L, Svanborg KD, et al. A stepped care strategy using buprenorphine and methadone versus conventional methadone maintenance in heroin dependence: a randomized controlled trial. Am J Psychiatry. 2007;164(5):797-803. Available at: http://ajp.psychiatryonline.org/cgi/ reprint/164/5/797. Accessed September 27, 2009.

21. Glabman M. Multiple therapies help curb opioid dependence. Manag Care. 2009;1(1):14-20. Available at: http://www.managedcaremag.com/ supplements/0812_opioids_workplace/opioids_in_the_workplace.pdf. Accessed January 19, 2010.

22. Network for the Improvement of Addiction Treatment. Available at: https://www.niatx.net/content/contentpage.aspx?NID=9. Accessed January 24, 2010. 